\title{
Surface biomass monitoring of rotational grazing in alpine grassland based on satellite Multi-spectral images
}

\author{
Shengfu Zhang ${ }^{1}$ \\ ${ }^{1}$ College of Computer Science, Qinghai Nationalities University, 810007 Xining, China
}

\begin{abstract}
The surface of the biomass monitoring is blocked rotational grazing land prerequisite for high scores (GF - 1) satellite multispectral image and artificial biomass index test, using the ENVI software GF1 or GF6 data (radiation calibration atmospheric correction of RPC orthographical correction), and then calculate the vegetation index (NDVI), NDVI can detect vegetation growth status, vegetation coverage and eliminate part of the radiation error manual data collection and statistical analysis, then normalized processing, the conclusion is obtained.
\end{abstract}

\section{Introduction of study area}

The study area is located in the eastern part of Qinghai Province, within the Sanjiangyuan Nature Reserve, and

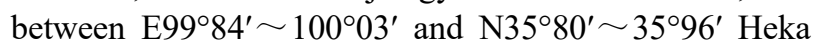
Town. There are various types of landforms in the territory, but mainly mountainous areas. The altitude is $2590 \sim 5305 \mathrm{~m}$. The annual average temperature is $0.5^{\circ} \mathrm{C}$, $6.1^{\circ} \mathrm{C}$, the winter is long and the summer is short, the average annual precipitation is about $240-600 \mathrm{~mm}$, the wind is heavy and sandy, the annual sunshine hours are 2670-2790 hours, and the solar radiation is strong. The grassland type is cold-tolerant and xerophyte, dominated by perennial clump grasses.

\section{Materials and method}

\subsection{Layout of grassland monitoring points}

1) The three pastures were set up. They are defined as Summer pasture, Autumn pasture, and Winter-Spring pasture. For each grassland, three representative plots with typical ecological distribution regions were selected, and each plot was divided into 9 regions for monitoring.

2) Each grassland is divided into 3 plots with a net fence to facilitate the grazing test in rotation.

3) The number of Tibetan sheep grazing in each grassland is calculated based on the carrying capacity of the forage experiment conducted in advance.

4) Monitoring points and numbers: The numbers uniformly adopt the format of "seasonal area numbersample area number-sample area number", such as Winter-Spring pasture, Autumn pasture, and Summer pasture as $\mathrm{A}, \mathrm{B}$, and $\mathrm{C}$ respectively. A-01 (sample plot number)-02 (sample plot number).

\section{Grassland detection indicators}

\subsection{Natural grassland monitoring indicators}

1) Rotate grazing in the order of the community, grazing for 7 days in each community in Summer, Autumn, Winter-Spring; continuous grazing in the season is divided into pastures with the same area in Summer, Autumn, Winter-Spring. 5 samples in each area were monitored. There are a total of 45 sample plots in each plot.

2)According to the stocking capacity, the rotation grazing grassland will graze 220, 310, 310 flocks in each community in summer, autumn, winter-spring. There are also 220, 310, and 310 sheep flocks on the grazing pastures in continuous season.

3) At the same time, we continuously measured the plots of rotation grazing and continuous grazing in the districts to make statistics on the amount of grass produced by the sample every week. From June 2018 to October 2019, the dynamic changes of grass production in each pasture can be obtained.

4) Available forage amount, usable area, yield per unit, total yield, availability, the total amount of fresh forage, and stock-carrying capacity of the experimental group and control group before and after grazing; the amount of forage required: quantity, sheep unit, the amount of fresh grass needed; the balance of supply and demand: forage amount and stocking capacity. 


\section{Monitoring method}

\subsection{Manual measurement}

According to the plots and indicators of the above grassland monitoring points, the data of the grazing area and continuous grazing grassland were collected successively in the sheep grazing.

\subsection{Remote sensing measurement}

High-resolution satellite monitoring is used to estimate the biomass of grassland biomass during the grazing of sheep. The data of rotation grazing, and continuous grazing grassland are collected and estimated, and the ground artificial monitoring data is used as a reference to correct the grassland biomass.

\section{Calculation and judgment method}

In accordance with the requirements of the "Technical Regulations for Grassland Resources Investigation in Qinghai Province", the project team calculated the theoretical stocking capacity of $333 \mathrm{mu}$ of natural grassland in Summer, Autumn, Winter-Spring, and the measured area, and combined the actual stocking statistics for calculating the overload rate based on the statistics of actual stocking capacity.

Reasonable stocking capacity of grassland: in a certain area of grassland and a certain time of use, under the condition of moderate grazing (or mowing) and maintaining sustainable grassland production, it can meet the requirements for the normal growth, reproduction, and production of livestock products. The number and time of livestock that can be supported. Existing (actual) livestock capacity: the actual number of standard livestock that a certain area of grassland can support in a certain period of use.

According to the above two concepts, the basis for judging the intensity of grazing is as follows: grassland grazing overload: actual stocking capacity $>$ reasonable stocking capacity; grassland grazing reasonable: actual stocking capacity $=$ or $\approx$ reasonable stocking capacity; grassland grazing latent loading: actual stocking capacity quantity $<$ reasonable stocking capacity.

\section{Collection and analysis of grassland resources}

\subsection{Statistical analysis of artificially collected grassland resources from 2018 to 2019}

By calculating the biomass from 2018 to 2019, the results of continuous grazing and area rotation grazing are shown in the following figure 1.

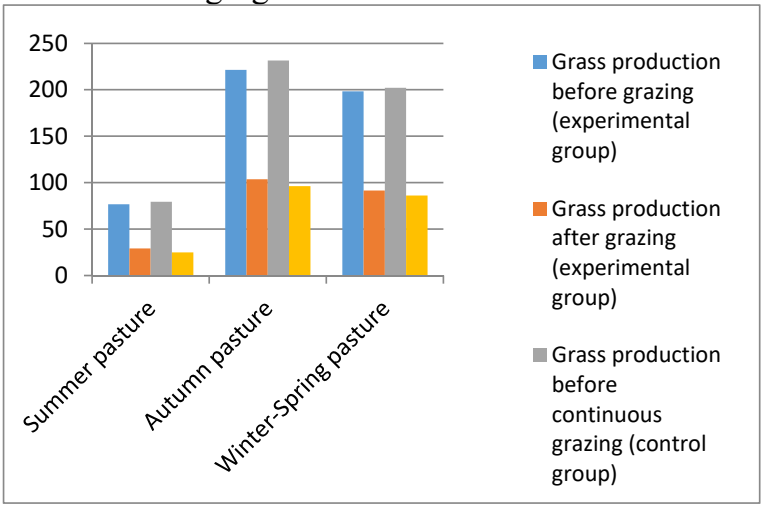

Figure 1. Unit (mu) grassland yield before and after grazing

The yield of grassland before and after grazing showed the grass yield per unit of grassland in summer, autumn, winter-spring from high to low, followed by Autumn, Winter-Spring, and Summer, indicating the number of livestock carried per unit of grassland. Under the premise of a fixed number, the size of the area or the length of grazing time should be adjusted. It can be used as an important basis when dividing the area of seasonal supergrasses.

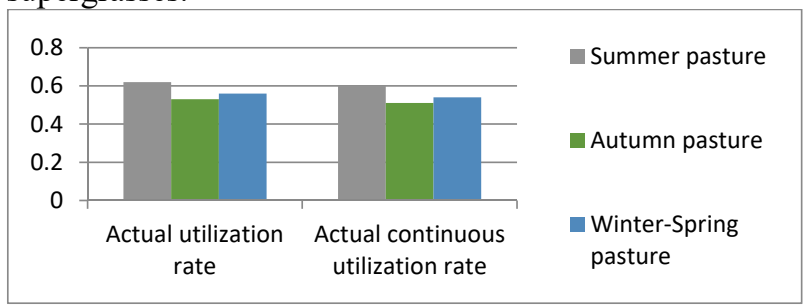

Figure 2. Unit (mu) grassland yield before and after grazing

The utilization rate of grassland before and after grazing shows the utilization rate of the pasture before and after grazing rotation and continuous grazing. It shows that the utilization rate of unit grassland in Summer, Autumn, Winter-Spring under the state of rotation grazing and continuous grazing is $0.62,0.53$, 0.56 and $0.60,0.51,0.54$, respectively, and the utilization rate of rotation grazing is higher than that of continuous grazing; The actual utilization rate does not change much from the standard utilization rate $(60 \%-65 \%)$. There was no significant difference compared with the control group, namely other herdsmen.

The way to improve the utilization rate is to arrange the grassland area and grazing time in Summer, Autumn, Winter-Spring according to the changes in the number of sheep, without considering other factors such as herdsmen grazing together to prevent wolf encroachment.

Furthermore, in terms of the composition of the grassland in each season, the unit (mu) grassland yield table shows that the grassland yield per unit $(\mathrm{mu})$ of the summer pasture area $\mathrm{A}, \mathrm{B}$, and $\mathrm{C}$ is different, and the utilization rate is also different. The number of livestock carried should also be different. Under the premise of a fixed number, the size of the area or the length of grazing time should be adjusted. 


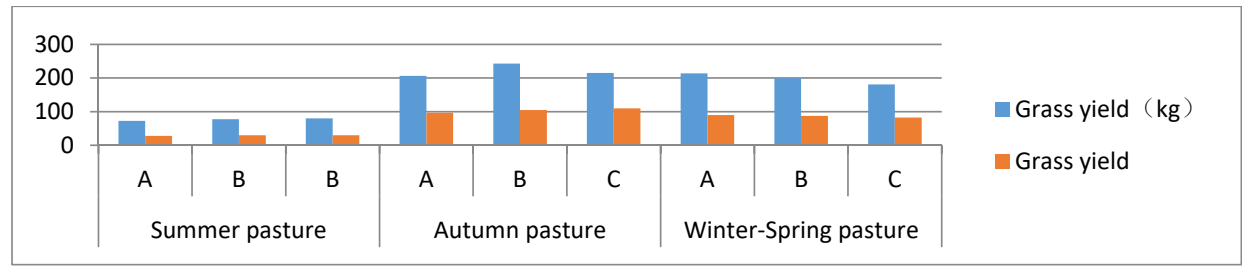

Figure 3. Grass yield in the rotation grazing area of the experimental group before and after grazing

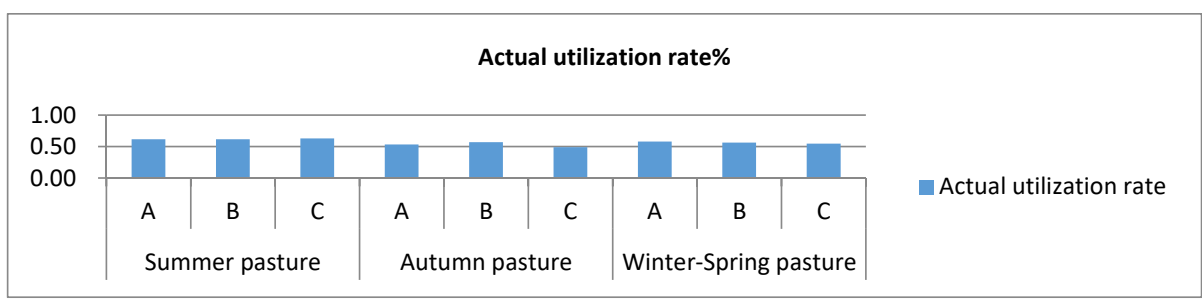

Figure 4. The utilization rate of grassland in the rotation grazing area before and after grazing

The yield table of grassland after grazing shows that under the condition that the yield and the number of herds basically match, the average value of summer grassland utilization rate is 0.62 , which is higher than the control group 0.60; the average value of autumn grassland utilization rate is 0.53 , which is higher than the control group 0.51; The average utilization rate of grassland in winter and spring was 0.56 , which was also higher than 0.54 in the control group. It shows that, overall, the division of grazing can increase the utilization rate of pasture. The utilization rate is directly related to the amount of grass produced, the number of livestock, and the length of grazing time.

Table 1. Forage balance

\begin{tabular}{|c|c|c|c|c|}
\hline \multirow{2}{*}{$\begin{array}{c}\text { Forag } \\
\text { e }\end{array}$} & \multicolumn{2}{|c|}{$\begin{array}{c}\text { Livestock capacity } \\
\text { of the test group }\end{array}$} & \multicolumn{2}{c|}{$\begin{array}{c}\text { Control group } \\
\text { stocking capacity }\end{array}$} \\
\cline { 2 - 5 } source & $\begin{array}{c}\text { Quantity } \\
\text { (sheep } \\
\text { unit) }\end{array}$ & $\begin{array}{c}\text { Propor } \\
\text { tion } \\
(\%)\end{array}$ & $\begin{array}{c}\text { Quantit } \\
\text { y (sheep } \\
\text { unit) }\end{array}$ & $\begin{array}{c}\text { Propo } \\
\text { rtion } \\
\text { (\%) }\end{array}$ \\
\hline $\begin{array}{c}\text { Summe } \\
\text { r } \\
\text { pasture }\end{array}$ & $\begin{array}{c}7.7940117 \\
5\end{array}$ & $\begin{array}{c}1.52823 \\
8\end{array}$ & $\begin{array}{c}12.30352 \\
5\end{array}$ & $\begin{array}{c}2.41245 \\
6\end{array}$ \\
\hline $\begin{array}{c}\text { Autum } \\
\text { n } \\
\text { pasture }\end{array}$ & 54.607473 & 3.79218 & 81.3825 & $\begin{array}{c}5.65156 \\
3\end{array}$ \\
\hline $\begin{array}{c}\text { Winter- } \\
\text { Spring } \\
\text { pasture }\end{array}$ & 11.033305 & 0.81728 & -9.72 & -0.72 \\
\hline
\end{tabular}

In general, the experimental group and the control group can basically achieve a balance under the same grazing area and herd number. However, there is a little difference in the composition and distribution of the animal carrying capacity between the experimental group and the control group.

With the increase in the utilization rate of unit grassland, the number of grazing can be increased and the carrying capacity can be increased. However, the output of each pasture is changing every year, and the number of herds is also changing. The match between the two is a dynamic match.

\subsection{8-2019 satellite data collection and analysis}

\subsubsection{Yield extraction}

(1) Data set

The GF-1 satellite is equipped with two $2 \mathrm{~m}$ resolution panchromatic $/ 8 \mathrm{~m}$ resolution multispectral cameras and four $16 \mathrm{~m}$ resolution multispectral cameras. The satellite's wide-range multispectral camera has a width of 800 kilometers.

The Gaofen-6 satellite is equipped with a $2 \mathrm{~m}$ panchromatic/8m multispectral high-resolution camera, a $16 \mathrm{~m}$ multispectral medium-resolution wide-format camera, a $2 \mathrm{~m}$ panchromatic $/ 8 \mathrm{~m}$ multispectral camera, and an observation width of $90 \mathrm{~km}$, more than $16 \mathrm{~m}$ the spectrum camera has an observation width of 800 kilometers.

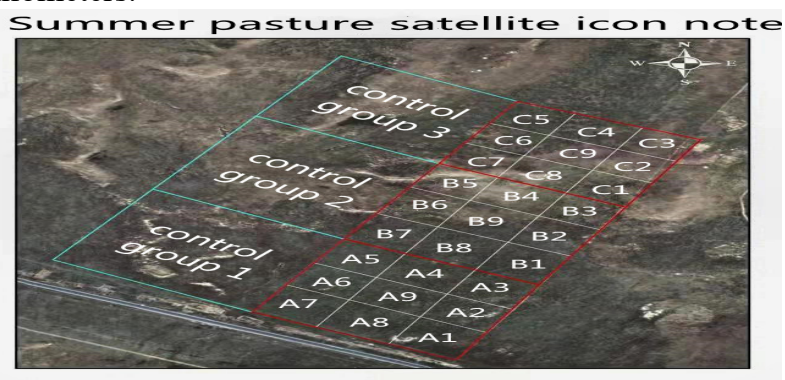

Figure 5. Summer pasture satellite icon note

\section{Autumn pasture satellite icon note}

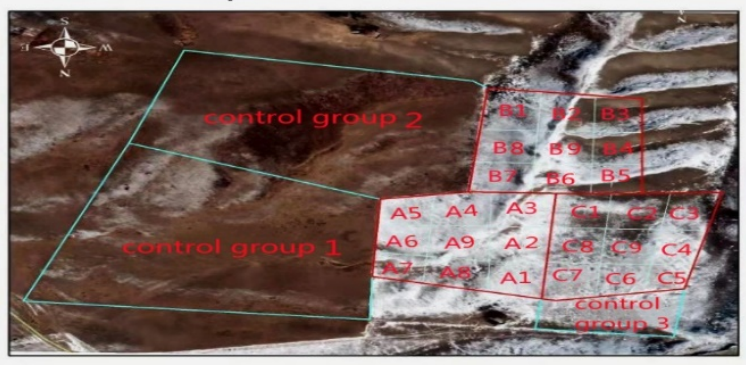

Figure 6. Autumn pasture satellite icon note 


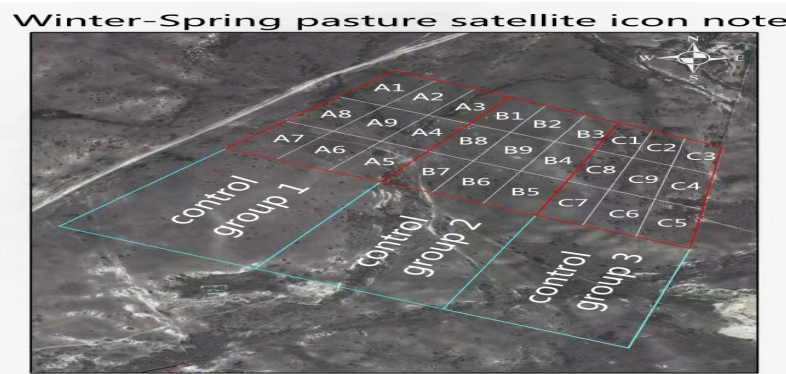

Figure 7. Winter-Spring pasture pasture satellite icon note

\section{(2) Research methods}

First, data were processed by GF1 or GF6 (radiation calibration, atmospheric correction, RPC ortho correction) under ENVI software, and then calculate (NDVI). NDVI can detect vegetation growth status, vegetation coverage, and eliminate some radiation errors. NDVI can reflect the background effects of the plant canopy, such as soil, wet ground, snow, dead leaves, roughness, etc., and is related to vegetation cover.Normalized vegetation index calculation model:

$$
N D V I=(N I R-R) /(N I R+R)
$$

(the reflectivity difference between the near-infrared zone and the red-light zone/the sum of the reflectivity between the near-infrared zone and the red light zone).GF1/GF6 data to calculate the normalized vegetation index model:

$$
\text { (float(b4)-b3)/(b4+b3) }
$$

NDVI value range: $-1<=\mathrm{NDVI}<=1$, a negative value means that the ground is covered by clouds, water, snow, etc., which is highly reflective to visible light; 0 means that there is rock or bare soil, etc., NIR and R are approximately equal; a positive value means that There is vegetation coverage, and it increases with the increase of coverage. Acquisition of NDVI:

(3) Construction of forage yield calculation model Use the NDVI result calculated by the image and use the raster calculator in the ARCGIS software to calculate the forage yield.Forage yield calculation model:

$$
Y=A * \exp (4.611 * N D V I)
$$

\subsubsection{Analysis of yield characteristics}

(1) Comparison of test entry and exit time with satellite data time

Table 2. Comparison of test entry time and satellite data time

\begin{tabular}{|c|l|l|l|l|}
\hline & $\begin{array}{c}\text { Test } \\
\text { admission } \\
\text { time }\end{array}$ & $\begin{array}{l}\text { Satellite } \\
\text { data time }\end{array}$ & $\begin{array}{c}\text { Test } \\
\text { exit } \\
\text { time }\end{array}$ & $\begin{array}{l}\text { Satellite } \\
\text { data time }\end{array}$ \\
\hline $\begin{array}{c}\text { Summer } \\
\text { pasture }\end{array}$ & July 27th & July 27th & $\begin{array}{l}\text { August } \\
17 \text { th }\end{array}$ & $\begin{array}{l}\text { August } \\
17 \text { th }\end{array}$ \\
\hline $\begin{array}{c}\text { Autumn } \\
\text { pasture }\end{array}$ & August & August & August & September \\
20th & 13 th & 26th & 7th \\
\hline $\begin{array}{c}\text { Winter- } \\
\text { Spring } \\
\text { pasture }\end{array}$ & September & September & October & October \\
21st & 12 th & 18th \\
\hline
\end{tabular}

(2) Analysis of forage yield in different seasons
Table III and Figure 8 show the pasture yields of the three experimental groups and the control group when the flocks of Summer pastures enter the farm. The forage yield of the experimental group was greater than that of the control group. When the sheep came out, the forage yield of the three experimental groups and the control group was higher than that of the control group. The forage yields of the experimental groups A and B were smaller than those of the control group.

Table 3. Grass yield before and after grazing in summer pasture

\begin{tabular}{|c|c|c|c|c|}
\hline $\begin{array}{c}\text { Time } \\
\text { series }\end{array}$ & $\begin{array}{c}\mathbf{0 7 / 2 7 / 2} \\
\mathbf{0 1 9} \\
\text { Enter }\end{array}$ & $\begin{array}{c}\mathbf{0 8 / 0 9 / 2 0} \\
\mathbf{1 9} \text { Exit }\end{array}$ & $\begin{array}{c}\text { Consum } \\
\text { ption }\end{array}$ & $\begin{array}{c}\text { Utiliza } \\
\text { tion } \\
\text { rate }\end{array}$ \\
\hline A & 44.08 & 24.81 & 19.27 & 0.44 \\
\hline $\begin{array}{c}\text { Contro } \\
\text { I group }\end{array}$ & 41.79 & 26.68 & 18.11 & 0.36 \\
\hline $\begin{array}{c}\text { Time } \\
\text { series }\end{array}$ & $\begin{array}{c}\mathbf{0 8 / 0 9 / 2} \\
\mathbf{0 1 9} \\
\text { Enter }\end{array}$ & $\begin{array}{c}\mathbf{0 8 / 1 7 / 2 0} \\
\mathbf{1 9} \text { Enter }\end{array}$ & $\begin{array}{c}\text { Consum } \\
\text { ption }\end{array}$ & $\begin{array}{c}\text { Utiliza } \\
\text { tion } \\
\text { rate }\end{array}$ \\
\hline B & 46.31 & 26.46 & 19.85 & 0.43 \\
\hline $\begin{array}{c}\text { Contro } \\
\text { I group }\end{array}$ & 47.60 & 29.58 & 18.02 & 0.38 \\
\hline $\begin{array}{c}\text { Time } \\
\text { series }\end{array}$ & $\begin{array}{c}\mathbf{0 8 / 0 9 / 2} \\
\mathbf{0 1 9} \\
\text { Enter }\end{array}$ & $\begin{array}{c}\mathbf{0 8} / \mathbf{1 7} / 20 \\
\mathbf{1 9}\end{array}$ & $\begin{array}{c}\text { Conter } \\
\text { ption }\end{array}$ & $\begin{array}{c}\text { Utiliza } \\
\text { tion } \\
\text { rate }\end{array}$ \\
\hline C & 48.94 & 28.68 & 20.26 & 0.41 \\
\hline $\begin{array}{c}\text { Contro } \\
\text { I group }\end{array}$ & 46.95 & 27.95 & 19.00 & 0.40 \\
\hline
\end{tabular}

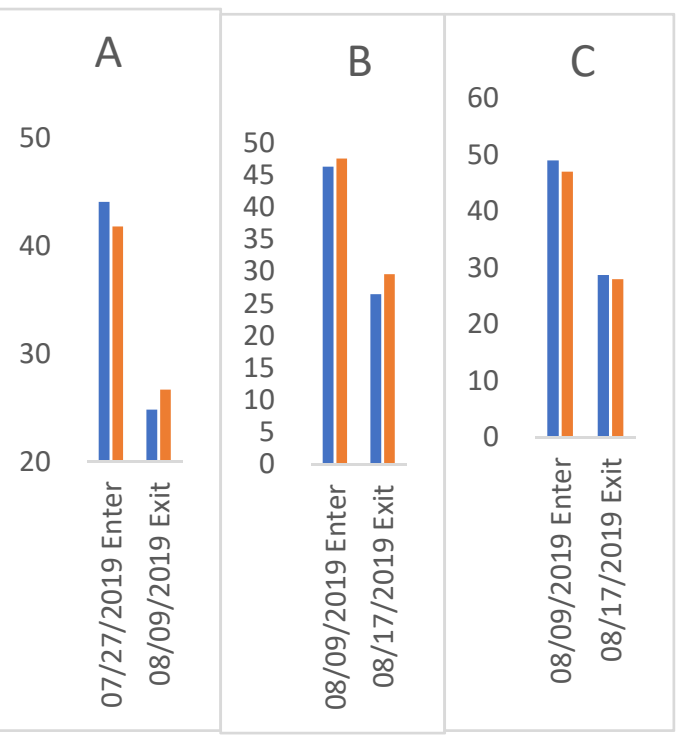

Figure 8. Comparison of grass yield before and after grazing in Summer pasture 


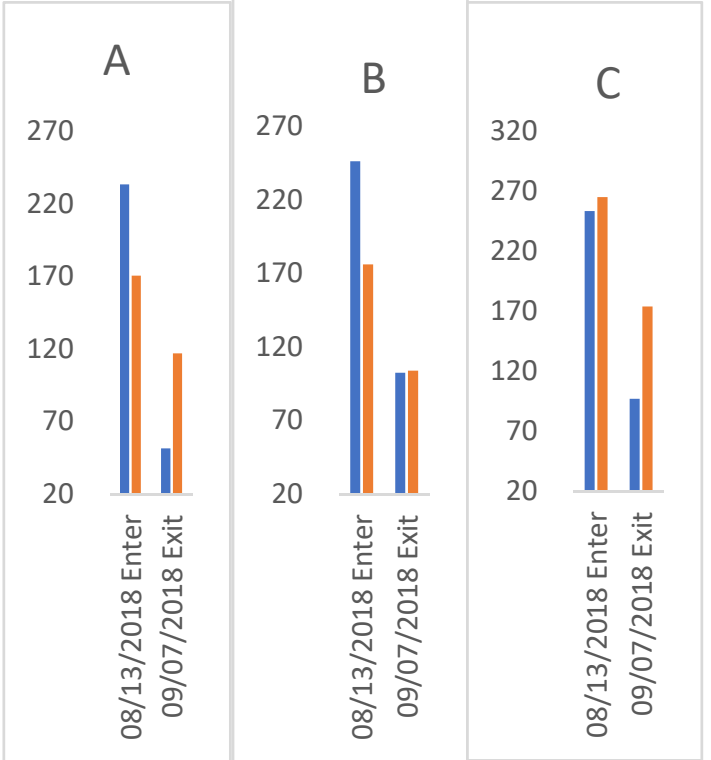

Figure 9. Comparison of grass yield before and after grazing in Autumn pasture

Figure 9 shows the forage yield of the three experimental groups and the control group when the sheep enter the field in Autumn. The forage output of test groups A and B was greater than that of the control group and the forage output of test group $\mathrm{C}$ was less than that of the control group. When the sheep are out of the field, the forage yields of the three experimental groups and the control group. The forage yield of the experimental group was less than that of the control group. The utilization rate of the experimental group was 47,17 , and 28 percentage points higher than that of the control group, respectively.

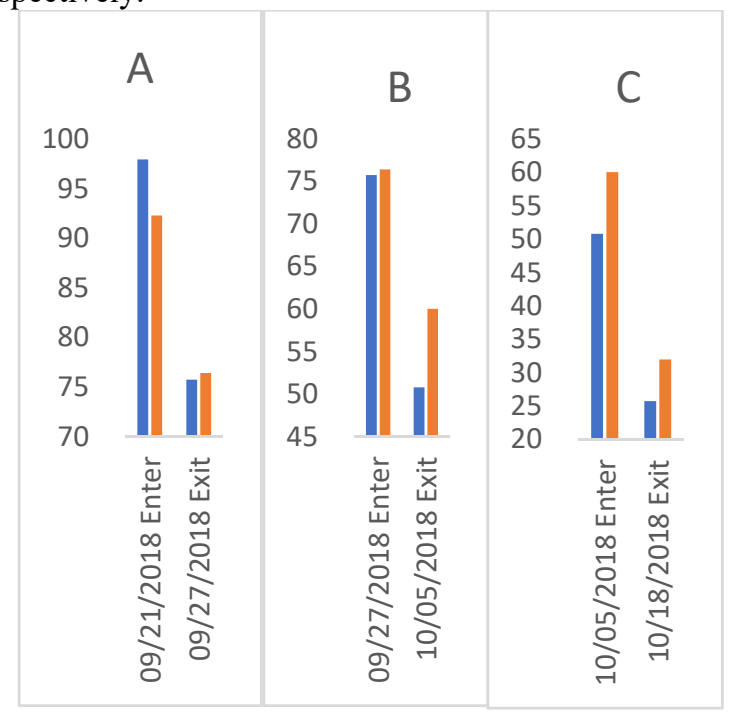

Figure 10. Comparison of grass yield before and after grazing in Winter-Spring pasture

Figure 10 shows the forage yield of the three experimental groups and the control group when the sheep enter the field in winter and spring: the forage yield of experimental group $\mathrm{A}$ is greater than that of the control group, and the forage yield of the experimental groups B and $C$ is less than that of the control group. When the sheep are out of the field, the forage yields of the three experimental groups and the control group. The forage yield of the experimental group was less than that of the control group. The utilization rate of the experimental group was 6,12 , and 2 percentage points higher than that of the control group, respectively.

(3) Comparative analysis of artificial and satellite data The significant difference between artificial and satellite data comparison analysis is within $5 \%$, indicating that there is no significant difference between the two.

\section{Conclusion}

The results of the experiment show that the utilization rate of rotation grazing is higher than that of continuous grazing, and that rotation grazing is an effective grazing method; forage yield is positively correlated with the vegetation index of the year. If the vegetation index is higher, then the forage yield is greater.

Data were processed by GF1 or GF6 under ENVI software and then calculate vegetation index. NDVI can detect vegetation growth status, vegetation coverage and eliminate some radiation errors. Verifying manual data as standard data is an effective method for verifying the effect of area rotation grazing; the implementation of the area rotation grazing method should fully consider the influence of local grassland types and distribution conditions, livestock structure, and herder labor.

\section{References}

1. Xu Minyun. Research progress on grassland stocking capacity: Dilemma and prospects of research on forage-livestock balance in China [J]. Acta Prataculturae Sinica, Vol. 23, No. 5, October 2014

2. Xu Minyun, Gao Lijie, Li Yunqi. Research progress on ground carrying capacity: parameters and calculation methods [J] Acta Prataculturae Sinica, August 2014, Volume 23, Issue 4

3. Li Qingfeng. Series of studies on grass-livestock balance management (3)-Reformation of grasslivestock balance accounting methods $[\mathrm{J}]$. Grass Industry Science, 2011, Vol. 28, Issue 12

4. Li Qingfeng, Qi Zhixin. A series of studies on foragelivestock balance management (5) - monthly dynamic changes of forage yield[J]. Grass Industry Science, 2012, Vol. 29, Issue 02

5. Sugiura R, Itoh A, Nishiwaki K, et al. Development of High-Throughput Field Phenotyping System Using Imagery from Unmanned Aerial Vehicle[C].2015 ASABE Annual International Meeting. American Society of Agricultural and Biological Engineers, 2015: 1.

6. Yun H, Kim H J, Park K, et al. Use of an UAV for Biomass Monitoring of Hairy Vetch[C].2015 ASABE Annual International Meeting. American Society of Agricultural and Biological Engineers, 2015: 1.

7. Torres-Sanchez, J., F.Lopez-Granados,A. I.De Castro, et al.Configuration and Specifications of an Unmanned Aerial Vehicle (UAV) for Early Site Specific Weed Management. Plos One,2013, 8 (3).

8. Gao Lin, Yang Guijun, Wang Baoshan, et al. 
Research on soybean leaf area index inversion based on UAV remote sensing images[J]. Chinese Journal of Eco-Agriculture, 2015(07): 868-876

9. Zhao De. Analysis and evaluation of forage resources and forage-livestock balance in Gonghe County, Qinghai Province[J]. Animal Husbandry and Feed Science, 2017, 38(8): 33-35 